\title{
Study on How to Improve the Quality and Efficiency of the Community Affairs in Xi 'an \\ Guanhua Dong
}

Xi'an University, NO1, Keji six Road, Yanta District of Xi'an, China,710065

email: 258332239@qq.com

Keywords: Community affairs; Quality and efficiency improving; Intelligence community

\begin{abstract}
Community governance is the cornerstone of national governance. The quality and efficiency of community affairs affect people's satisfaction and community governance. The action of improving the quality and increasing the efficiency of communities affairs in $\mathrm{Xi}$ 'an has achieved certain results, but there are still bottlenecks such as too much community service acceptance and too dispersed departments providing services, difficulty in sharing public service information, difficulty in guaranteeing the individual needs of the masses, and low utilization degree of information platform. It is necessary to draw lessons from other provinces and cities, especially online experience, summed up to promote $\mathrm{Xi}$ 'an part of the community model, adopt the public advice, adopt the method of integrated innovation, absorb other model strengths,try to build a new intelligent community model,help with $\mathrm{Xi}$ 'an "Solve everything online" construction, improve the effectiveness and efficiency of community affairs.
\end{abstract}

\section{西安市基层社区事务办理提质增效问题研究}

\author{
董冠华 \\ 西安文理学院经济管理学院, 雁塔, 西安, 陕西, 中国
}

email: 258332239@qq.com,

关键词：社区事务; 提质增效; 智慧社区

中文摘要. 社区治理是国家治理的基石, 基层社区事务办理的质量和效率, 影响着人民群众 的满意度和社区治理乃至国家的效益。西安市基层社区提质增效行动取得了一定成效，但仍 然存在着社区服务受理量过大的同时提供服务的部门过于分散、公共服务信息难以共享、群 众个体化需求难以保障、信息化平台利用程度较低等瓶颈。可以借鉴上海、吴忠等其他省市 “一口受理” 式、网上办理经验，总结推广西安市部分社区试行的智慧社区模式，采纳公众 建议, 采用集成创新的方法, 构建符合西安实际且吸纳其他模式长处的智能西安社区事务办 理模式，助力西安 “一网通办”建设，切实提高基层社区事务办理的效能与效率。

\section{1. 引言}

建设西安市居民满意的社区事务办理体系，促进基层社区事务办理提质增效，是提升国 家社会治理能力和治理水平的体现, 也是西安文明程度高低的反映。西安强化为民服务宗旨, 提升社区建设与服务质量, 基层社区事务办理质量与效益得到提升, 但与大西安建设和普通 居民的要求还存在差距。西安要进一步优化体制机制, 转变基层社区职能, 全面加快基层社 区事务办理提质增效步伐。 


\section{2. 西安基层社区事务办理的现状与问题}

做好便民利民的社区服务，是西安社区工作的重要职责。为了进一步提高社区事务办理 质量、效率和水平，掌握西安基层社区事务办理提质增效的现状与存在的问题，我们选取西 安雁塔区、长安区、䨋邑区三区较为典型的基层社区, 就社区事务办理情况进行了调查。

\section{1 西安基层社区事务办理现状调查分析}

调查共回收有效问卷250份。调查结果说明较多居民不了解所在社区居委会办公地址, 多 数居民通过户外展示了解本社区情况，居民对社区开展的便民服务活动了解程度不高; 居民 的意见主要集中在社区服务项目不适用；社区服务中，居民认为最实用的项目主要是居民养 老、居民医保、保障房申办、低保残联等; 居民使用所在社区数字化信息服务平台办理具体 事务的比例有待提升，西安市可以以智能社区服务为主要抓手，在全市进一步推广社区数字 化信息服务平台; 多数居民对社区工作基本满意, 居民对社区事务办理质量与效率基本满意。 与社区工作与社区工作者服务态度和服务质量满意度相比, 社区事务办理质量与效率的不满 意率是最低的, 部分说明西安基层社区提质增效取得一定成效。

\section{2 西安基层社区事务办理存在问题分析}

依托前期扎实调研, 经过梳理和深入分析, 发现西安基层社区事务办理提质增效主要存 在以下瓶颈。

1.社区服务业务较为分散。基层社区事务服务领域仍然存在分业务受理现象，居民为获取 公共服务必须往来于多个部门之间。

2.公共服务信息不能共享。不同职能部门不能很好地实现信息共享, 信息系统缺乏对接, 缺乏统一的数据共享平台与基础数据支撑。多个信息系统重复录入同一数据, 增加居民办事 时间成本。

3.居民个性化需求不能够满足。基层社区提供的服务缺乏个性化。社区主要提供“托底型” 公共服务, 很难满足个性化的需求。

4.基层社区服务受理量大。基层社区服务项目越来越多，受理量持续剧增，基层社区工作 人员压力过大，影响服务质量提升与满足个性化服务需求。

\section{3. 西安基层社区事务办理提质增效借鉴}

\section{1 借鉴其他省市的成熟模式}

1.上海市徐汇区“一口受理”式社区事务受理服务中心建设是以信息化手段为支撑，以制 度建设为保障, 以健全管理机制为核心, 不断完善社区事务受理服务中心“一门式服务、一口 式受理、一体化运作”的运行机制。

2.上海杨浦区智慧社区利用信息技术，为社区居民提供高效、便捷和智慧的服务，提升社 区居民的体验度和感受度。推行社区事务“网上办”的“全事项+全覆盖”的服务能级。

3.上海全市各街镇(乡)的社区事务受理服务中心“全市通办”模式，社区事务办理推行“一 头管理、一门办理 、一口受理、全年无休、全市通办”。加速推进“互联网+政务服务”改革, 摸准群众实际需求, 紧密对接相应服务。主动跨前, 紧密协作, 自我加压, 合力推进, 确保 各项措施落地见效。

4.吴忠市“不见面、马上办”审批模式，实现基层社区事务办理提质增效。抓住“放管服”牛 鼻子, 推进政府职能转变, 进一步提升行政审批效率, 增强群众获得感, 努力做到网上办、 集中批、联合审、区域评、代办制、不见面，扩大网上审批、网上办事。 


\section{2 普及推广创新型社区服务模式}

西安市桃园路街办牵头, 由劳动一坊社区与信息公司共同打造了互联网云端智慧社区管 理服务平台。“智慧社区”设置了社区党建、社区服务、物业服务、志愿服务、查询服务、建言 献策等多个板块, 包含了社区新闻通知、社区活动预告、政策法规、办事指南、保障在线申 请、困难求助、预约办事、投诉建议、在线购物与点餐订座等服务内容。居民只需用手机微 信扫取专属二维码就可进入, 实名注册后便可享受智慧社区带来的方便与乐趣。智慧社区云 平台的上线，切实提高了居民的满意度和幸福感，提高社区为民服务的工作效率，打造便捷 高效的数字社区。

\section{4. 西安基层社区事务办理提质增效对策}

\section{1 构建智能社区事务办理的西安模式}

构建智能西安社区事务办理的新模式。西安可以吸纳全国其他省市基层社区事务办理的 成功经验, 采用集成创新的方法, 构建既符合西安实际, 又能尽可能吸纳其他模式长处的智 能西安社区事务办理模式，让居民不跑路、不跨区、不久等、不生气、不费心，能够舒心顺 畅地办好相关事务。在西安居民事务办理需求数量快速增加、个性化服务要求更高、基层社 区事务办理力量有限的条件下, 采用智能服务, 是西安构建基层社区事务办理新模式的主要 着力点。

西安智能社区事务办理模式的特点应该是：一是立足实际，充分调查研究西安基层社区 事务办理的现状与问题，做到有的放矢; 二是目标明确，以西安基层社区事务办理提质增效 为目标；三是兼容并蓄，充分借鉴“一口受理”模式，网上办、不见面模式，“全事项+全覆盖” 模式，以及“全市通办”模式，将这些成熟模式的精华融为一体; 四是建立负面清单制度，所有 不能纳入智能社区事务办理的事项或环节，必须设置负面清单，逐步减少负面清单。负面清 单上的项目或环节数量成为考评部门与区县的依据。遵循上述要点, 形成适应西安基层社区 事务办理实际，有利于提质增效的西安模式。

智能西安社区事务办理模式的内涵应该是：一是智能西安基层社区事务办理全覆盖；二 是智能西安基层社区事务立即办; 三是智能西安基层社区事务办理西安通; 四是智能西安基 层社区“一站受理”式事务办理机制; 五是智能西安基层社区事务办理不见面。

推行社区事务“网上办”的事项全覆盖，居民可在线上办理社区事务所有事项。居民只需 拍摄上传申请材料图片，提交并经工作人员后台审核后，最多跑一次，即可快速办理成功所 需办理事项。让“数据多跑路、群众少跑腿、办事像网购”, 在线实现事项咨询、资料预审，有 效节省现场办理时间。将线下办理事务纳入负面清单，逐步减少线下办理事务的事项数量。 努力做到网上办、代办制、不见面，普及网上审批、网上办事。

\section{2 采纳社会公众对社区服务的建议}

第一，提供老年人需要的社区服务。有调查对象提出希望工作人员对居民小区中老人居 多的小区开办老年食堂，便利老年人生活。中国进入老龄化阶段后，社区老年居民的需求要 得到有效满足, 必须引入市场机制。西安市可以建立基层社区老年服务基金, 利用基金支持, 吸引社会力量参与老年人服务提供, 开拓老龄市场, 加大管理力度, 使社区服务紧贴居民需 求。

第二，构建覆盖全部社区的微信群或QQ群等线上交流方式。部分调查对象希望社区工作 人员建立微信群或QQ群, 及时通知一些便民事务, 方便居民办理。不仅要提供微信群等智能 平台以提升沟通效率, 还要紧跟智能技术发展步伐, 进一步学习其他省市好的做法, 尽可能 开拓更多智能服务方式，让不同居民都能够最有效地获得相关服务。 
第三，了解居民真实需求。部分调查对象希望社区工作人员不定时走访居民家庭，进行 深入交流，明白居民的真实需要，真正为居民做实事。建立社区工作人员与居民定期不定期 互动机制，采用线上线下无障碍交流方式，第一时间获得居民的反馈与诉求。

第四，提供社区文化支持。调查对象诉求中，提到希望社区工作领导尽可能拨付经费， 举办文化活动，促进邻里关系和谐。建立基层社区文化服务基金，把弘扬新时代中国特色社 会主义优秀文化作为西安基层社区建设的亮点，形成基层社区文化建设的西安模式。

第五，争做基层社区服务店小二。部分调查对象希望社区人员定时学习，提高素质，增 强服务意识。在条件允许的条件下，进一步充实基层社区服务力量，配备业务精、态度好、 素质高、能力强的年轻骨干，招考适应新时代智能技术服务需求的基层社区工作人员，改变 基层服务工作人员平均年降较大、对智能服务技术掌握不足、很难适应智能西安社区服务要 求的被动局面, 加大新生服务力量, 提升服务水平, 适应西安基层社区全面智能化服务的趋 势。

\section{3 其他需要改进的基层社区服务内容}

首先, 建立基本信息共享机制。在保护居民隐私的条件下, 建立西安居民信息大数据库, 居民信息实现统一管理, 尽可能让各部门在办理业务过程中能够分享基本信息。办事人基本 信息管理、事务受理、数据共享、绩效管理、证照管理等功能集于一体。

其次，发展市场社区服务组织。针对日益增长的多元化服务需求，探索社区组织参与社 区服务的机制，拓展参与社区管理和社区公共服务的途径。建立市场化社区服务组织发展基 金，激活提供个性化社区服务的市场，培育社团、行业组织、社会中介组织、志愿者服务团 队等社区服务组织, 鼓励社会力量提供更高质量的社区服务。依靠市场和社会力量, 更有效 地提供个性化服务。

再次，制定社区服务应急预案。为防止办理社区服务可能出现的客流高峰导致居民排长 队、久等后不能及时办结等突出问题, 社区要采取网上预约、现场领号、必要时延长工作时 间等方式提前做好应急预案, 化解风险, 提升居民满意度。

最后，加大智能服务能力培训。解决基层社区事务办理提质增效问题的根本出路是利用 信息技术，要解决基层服务人员的过重压力，也需要充分利用智能技术。加大对社区基层服 务人员的信息技术与智能系统应用能力培训，在不大幅增加成本的条件下提质增效。推广社 区干部学院, 针对社区干部精准研发培训课程, 促进社区干部教育培训的常态化与制度化, 确保基层社区干部不断开阔思路, 更新知识, 更好地服务基层群众, 不断提升群众满意度。

\section{4 提升社区管理人员数量和质量}

在社区工作当中，有时候，人员数量不够会造成一些不必要的麻烦，所以社区应该在每 年的恰当时间，招募一些大学生来社区见习或者实习，一来可以帮助社区工作人员减轻他们 的工作量, 二来还可以给大学生一个接触社会机会。当前社区管理人员对社区的基本素质和 知识面还有所欠缺, 这将会对老年人文化生活的文化环境产生影响, 所以提高社区管理人员 整体质量也显得尤为重要。

\section{References}

[1] Jianyu $\mathrm{Xu}, \mathrm{Xiaolan} \mathrm{Ji}$,Discussion on Inherent Power of Urban Community Governance, Zhongzhou Journal, vo5, pp. 21-28, 2018.

[2] Fakui Zhu,Yidong Zhu,Innovation of General Social Work Model to Promote Quality and Efficiency in the Community, China Civil Affairs, vo23, pp.62-67, 2015.

[3] Wanqiang Xu, Min Li,Research on the Governance Structure of Urban Communities Based on Shared Value Orientation, Ningxia Social Science, vol 3, pp. 121-129, 2019. 